\title{
Curing Reactions of Bismaleimide Resins Catalyzed by Triphenylphosphine. High Resolution Solid-State ${ }^{13}$ C NMR Study
}

\author{
Sumio Shibahara, Takashi Enoki, ${ }^{*}$ Takahisa Yamamoto, ${ }^{* *}$ Jiro Motoyoshiya, ${ }^{* * *}$ \\ and Sadao HaYASHI $* * *$ \\ Kobe Fundamental Research Laboratory, Sumitomo Bakelite Co., Ltd., \\ 1-5, Murotani 1-chome, Nishi-ku, Kobe 651-22, Japan \\ * Industrial Resin Laboratory, Sumitomo Durez Co., Ltd., \\ 2299-1, Takayanagi, Fujieda, Shizuoka 426, Japan \\ ** Sumibe Techno Research Co., Ltd., \\ 495, Akiba-cho, Totsuka-ku, Yokohama 245, Japan \\ *** Faculty of Textile Science and Technology, Shinshu University, \\ 3-15-1 Tokida, Ueda 386, Japan
}

(Received January 19, 1996)

\begin{abstract}
The curing reactions of bismaleimide resins consisted of $N, N^{\prime}-4,4^{\prime}$-diphenylmethanebismaleimide (BMI) and $o, o^{\prime}$-diallylbisphenol-A (DABA) in the presence of triphenylphosphine (TPP) as a catalyst were investigated. DSC measurements showed that the catalytic effect of TPP on the curing reaction of BMI was more in the presence of DABA than in its absence. In order to explore this curing reaction, $N$-phenylmaleimide (PMI) and $o$-allylphenol (AP) were selected as model compounds. The products of the PMI/TPP system were oligomers and polymers of PMI, whereas the main product of the PMI/AP/TPP system was the PMI trimer which had the five-membered ring formed via the phosphonium ylide intermediate. In these model reactions, ${ }^{13} \mathrm{C}$ NMR was found to be useful to distinguish between trimerization and polymerization of PMI. On the basis of the results of the model reactions, the curing reactions of bismaleimide resins were investigated by high resolution solid state ${ }^{13} \mathrm{C}$ NMR techniques. In the BMI/TPP system, maleimides polymerize above $175^{\circ} \mathrm{C}$, but the polymerization does not proceed at $120^{\circ} \mathrm{C}$. On the other hand, maleimides trimerize above $120^{\circ} \mathrm{C}$ in the presence of DABA and TPP. The mechanism of the trimerization is briefly discussed.

KEY WORDS Solid-State Nuclear Magnetic Resonance / Curing Reaction / Bismaleimide / Triphenylphosphine / Allyl Phenols / Model Reactions / Differential Scanning Calorimetry /
\end{abstract}

Bismaleimide resins are widely applied in multilayer print circuit boards and advanced composite materials because of their good heat-resistance. However, the main disadvantage is their brittleness due to high crosslinking density. In order to reduce brittleness, modification has been made by an aromatic diamine such as diaminodiphenylmethane or a diallyl compound such as diallylbisphenol-A. ${ }^{1}$ Another disadvantage is poor curability. Thus, the resins are cured at a temperature higher than $200^{\circ} \mathrm{C}$. The use of catalysts such as imidazoles, organic peroxides and tricoordinate phosphines has been studied to lower the curing temperature. ${ }^{2,3}$ However, detailed descriptions are not available as to the structures of the cured resins and the reaction mechanism. This would be due to the insolubility of the cured resins in various organic solvents, preventing the study of the reactions and analysis of the structures of the products.

Recently, solid state NMR with CP/MAS (cross polarization/magic angle spinning) technique, developed by Schaefer, ${ }^{4}$ has been applied to the analysis of insoluble polymers such as cured thermoset resins. ${ }^{5}$ According to this technique, we studied a series of the curing reaction of bismaleimide resins and reported the curing reactions of amine-modified bismaleimide ${ }^{6}$ and the effects of imidazole catalyst on bismaleimide/epoxy resin blend system ${ }^{7,8}$ based on the model reactions. ${ }^{9-12}$ We also found that the trimer of $N$-phenylmaleimide (PMI) was a chief product in the reaction of PMI and $o$-allylphenol (AP) in the presence of tripheylphosphine (TPP). The cured maleimide resin containing partly trimerized structure makes it possible to reduce brittleness while maintaining heat-resistance. This report describes the detailed curing reactions of bismaleimide resins catalyzed by TPP on the basis of model reactions and analysis by high resolution solid-state ${ }^{13} \mathrm{C}$ NMR and DSC (differential scanning calorimetry) of curing systems.

\section{EXPERIMENTAL}

Materials

$N, N^{\prime}-4,4^{\prime}$-Diphenylmethanebismaleimide (BMI) (Sumitomo Chemicals Inc.) was recrystallized from chloroform-methanol. $o, o^{\prime}$-Diallylbisphenol-A (DABA), PMI, and $N$-p-hydroxyphenylmaleimide (HPMI) were purchased from Mitsui Toatsu Chemicals Inc. TPP and AP used were analytical grade reagents. $N$-Phenyltriphenylphosphoranylidenesuccinimide (phosphorus ylide) was prepared from TPP and PMI in a known way. ${ }^{13}$

\section{DSC Measurements}

A Seiko Instruments Inc. Model 200 differential scanning calorimeter was used to evaluate the thermal behavior of the bismaleimide resins. The measurements were done at a heating rate of $10^{\circ} \mathrm{C} \mathrm{min}^{-1}$ in nitrogen atmosphere.

\section{Analysis of Model Reactions Products}

Model reactions were carried out in a $100 \mathrm{ml}$ flask equipped with condenser and stirrer. The reaction products were fractionated by GPC and then each fraction 
was identified by field desorption mass spectrometry (FD-MS) and liquid NMR. GPC conditions were as follows: Model, Japan Analytical Inc. LC-08; column, JAIGEL-2H; eluent, chloroform; detector, refractive index. FD-MS spectra and liquid NMR data were obtained with Hitachi model M-80B and with JEOL JNM-GSX400 spectrometer, respectively.

\section{${ }^{13}$ C Solid-State NMR Measurements of Cured Resins}

After BMI or BMI/DABA was mixed with TPP as the catalyst, the mixture was cured at the temperatures stated later for $10 \mathrm{~min}$ in a air oven. The cured samples were freeze-crushed to a powder for packing into the magicangle spinning (MAS) rotor of the JNM-GSX400 NMR spectrometer. High resolution solid-state ${ }^{13} \mathrm{C}$ NMR spectra were obtained at room temperature by crosspolarization/magic angle spinning ( $\mathrm{CP} / \mathrm{MAS})$. The measurement parameters were as follows: contact time, $2 \mathrm{~ms}$; repetition time, $5 \mathrm{~s}$; spinning rate, about $6.3 \mathrm{kHz}$.

\section{RESULTS AND DISCUSSION}

\section{Effects of TPP Catalyst on the Reactivity of Bismaleimide Resin}

To explore the effects of the TPP catalyst on the reactivity of bismaleimide resin, we measured DSC of the curing reaction of BMI. The DSC curves of BMI and BMI/DABA systems are shown in Figure 1. The exothermic peak for curing reaction of BMI without a catalyst was observed at $233^{\circ} \mathrm{C}$. In the BMI system catalyzed by TPP, an exothermic peak was observed at $168^{\circ} \mathrm{C}$. TPP catalyst clearly lowered the curing temperature of BMI. The exothermic peak of the BMI/DABA system without catalyst was observed at $261^{\circ} \mathrm{C}$. This peak temperature is higher than that of the BMI without catalyst. However, in the BMI/DABA system catalyzed by TPP, an exothermic peak was observed at $111^{\circ} \mathrm{C}$. This peak temperature is lower than that of BMI catalyzed by TPP. These results suggest that the effect of TPP catalyst on the reactivity of bismaleimide resin is influenced by the presence of DABA.

Model Reactions by Monofunctional Compounds in the Presence of TPP

To clarify the curing reaction of bismaleimide resin in

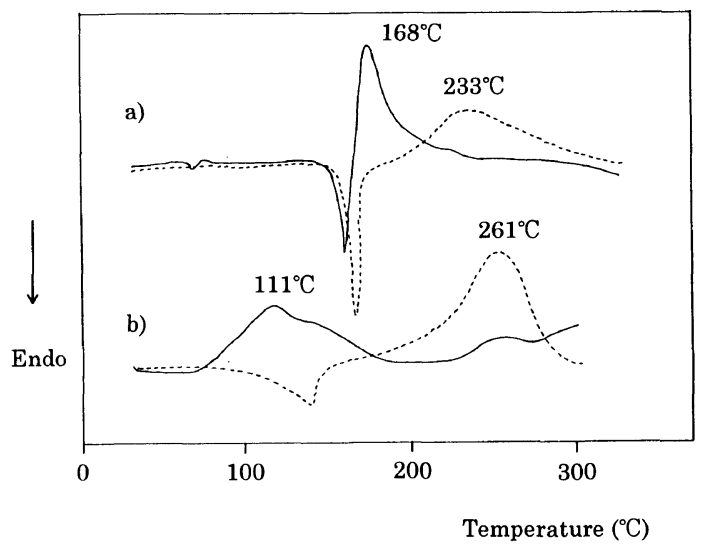

Figure 1. DSC thermograms of bismaleimide resins catalyzed by TPP: (a) BMI systems; (b) BMI/DABA systems; straight lines, resins with TPP catalyst; dotted lines, resins without catalyst the presence of TPP, we investigated reactions of the model systems using monofunctionalized compounds as shown in Table 1. After the reactions, the products were fractionated by GPC, and each fraction was identified by FD-MS and liquid NMR.

Figure 2 shows GPC chromatograms and compositions of the reaction products treated at $175^{\circ} \mathrm{C}$ for 10 min. In PMI/TPP system, the oligomer and polymer of PMI were obtained. In the PMI/AP/TPP system, the trimer of PMI was mainly obtained, and only a small amount of ene reaction product ${ }^{12,14}$ of PMI and AP and the polymer of PMI were obtained. The FD-MS spectrum of the PMI trimer showed a molecular ion peak at $m / z=519$. Figure 3 shows ${ }^{13} \mathrm{C}$ NMR spectra of the PMI trimer by DEPT (distortionless enhancement by polarization transfer) technique. The spectra showed a methylene signal at $30 \mathrm{ppm}$, methyne signals at $48 \mathrm{ppm}$ and $52 \mathrm{ppm}$, and a quarternary carbon signal at $54 \mathrm{ppm}$. This spectral pattern of PMI trimer agrees with that of the five membered trimer shown by Maes ${ }^{15}$ recently, which was formed in the thermal curing of the monofunctional maleimide-ended model compound. Consequently, the PMI trimer was identified as a cyclopentane derivative with a spiro-structure. The mech-

Table I. Curing systems and model systems

\begin{tabular}{cc}
\hline Curing systems & Model systems \\
\hline BMI/TPP & PMI/TPP \\
$(100 / 2)$ & $(100 / 2)$ \\
\hline BMI/DABA/TPP & PMI/AP/TPP \\
$(100 / 50 / 2)$ & $(100 / 50 / 2)$ \\
\hline
\end{tabular}
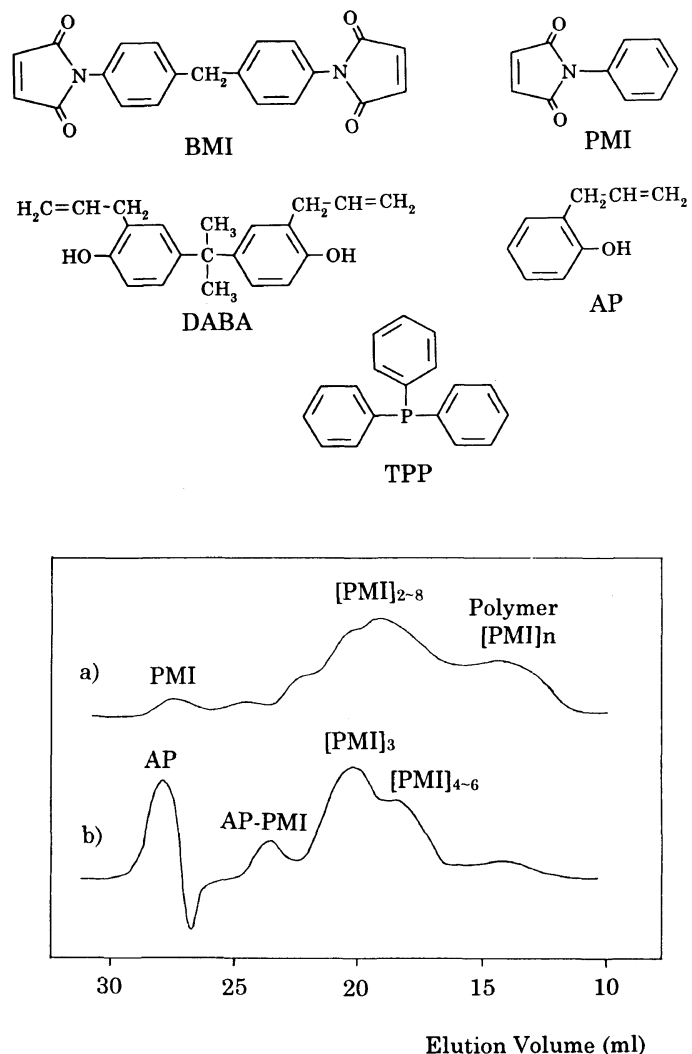

Figure 2. GPC chromatograms of the products reacted at $175^{\circ} \mathrm{C}$ for 10 min: (a) PMI/TPP system; (b) PMI/AP/TPP system. 


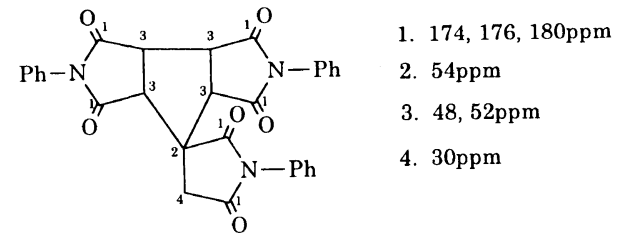

a)

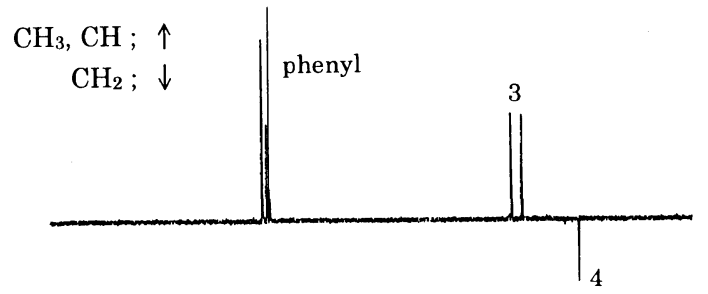

b) $\mathrm{CH} ; \uparrow$ phenyl

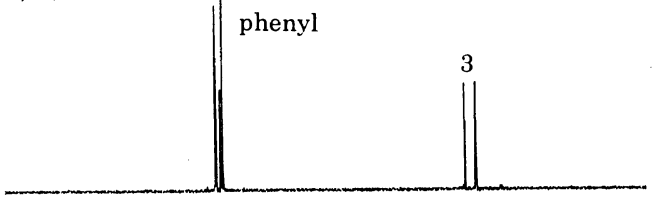

c)

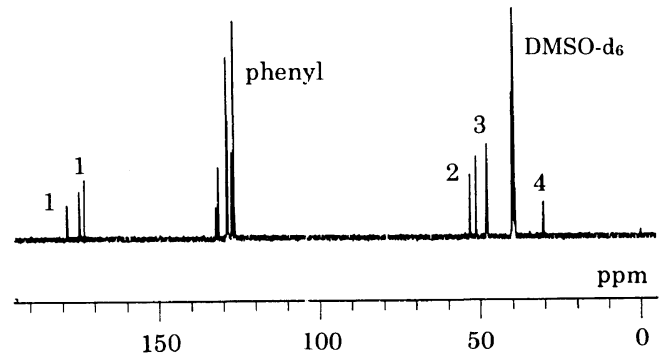

Figure 3. ${ }^{13} \mathrm{C}$ NMR spectra of the PMI trimer in dimethylsulfoxide$d_{6}$ : (a) DEPT 135 spectrum; (b) DEPT 90 spectrum; (c) normal ${ }^{13} \mathrm{C}$ NMR spectrum.

anism of formation is discussed later.

Figure 4 shows the ${ }^{13} \mathrm{C}$ NMR spectrum of the PMI polymer formed in the PMI/TPP system as well as that of the PMI trimer. The spectrum of the PMI polymer shows a broad peak around $44 \mathrm{ppm}$ ascribed to the methyne carbon and the spectrum pattern is quite different from that of the PMI trimer especially in the $30-50 \mathrm{ppm}$ region. This suggests that ${ }^{13} \mathrm{C}$ NMR spectra should provide useful information for distinction between trimerization and polymerization of maleimides.

The model reactions of PMI with AP showed that the reactions of maleimides catalyzed by TPP are influenced by the presence of allylphenols; the polymerization of maleimide proceeds without allylphenols, while the trimerization of maleimide mainly proceeds in the presence of allylphenols.

\section{Solid-State ${ }^{13}$ C NMR Studies of Curing Reactions of Bismaleimide Resin Catalyzed TPP}

As mentioned for the model reaction, ${ }^{13} \mathrm{C} N M R$ spectra in the $30-50 \mathrm{ppm}$ region were useful for the distinction between the polymerization and trimerization of maleimides. The spectral pattern due to carbonyl signal changed from $170 \mathrm{ppm}$ of PMI to the $174-180$ ppm region of the PMI trimer and the PMI polymer (Figure 4). The previous paper showed the assignment of $\mathrm{CP} / \mathrm{MAS}{ }^{13} \mathrm{C}$ NMR spectrum of BMI and spectral changes during the curing of BMI. ${ }^{5}$ The spectrum of cured BMI shows a new carbonyl peak at $176 \mathrm{ppm}$,
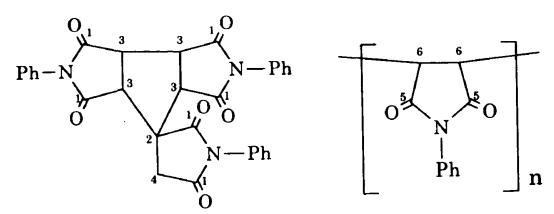

1. $174,176,180 \mathrm{ppm}$

2. $54 \mathrm{ppm}$

3. $48,52 \mathrm{ppm}$

4. $30 \mathrm{ppm}$

5. $176 \mathrm{ppm}$

6. $44 \mathrm{ppm}(\mathrm{b})$

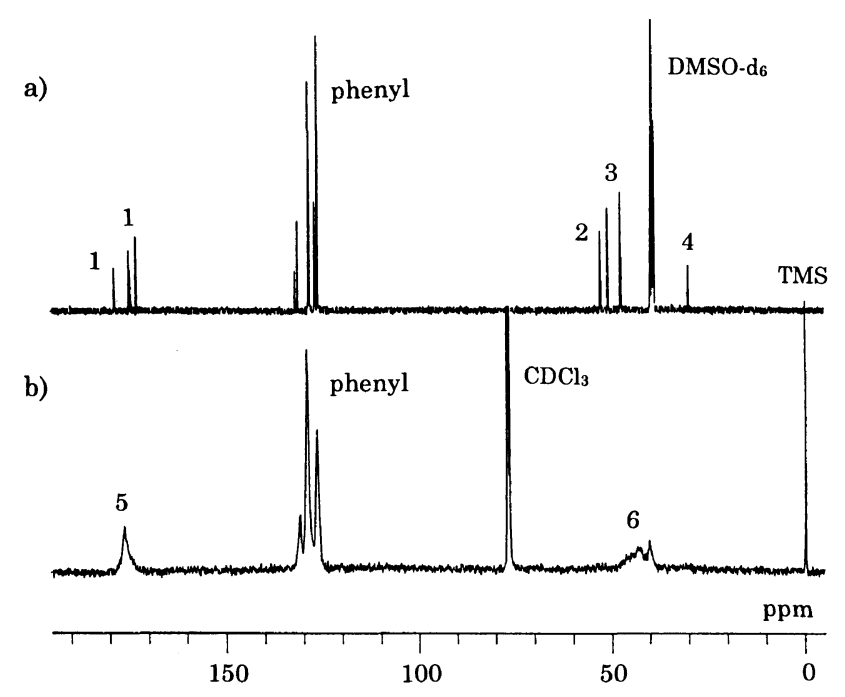

Figure 4. ${ }^{13} \mathrm{C}$ NMR spectra of (a) the PMI trimer in dimethylsulfoxide- $d_{6}$ and (b) the PMI polymer in chloroform- $d$.

and a new broad signal around $45 \mathrm{ppm}$ ascribed to a methyne carbon formed by the polymerization of double bond of maleimide. On the basis of this information, we investigated the curing reaction of bismaleimide resins in the presence of TPP as catalyst by using high resolution solid-state ${ }^{13} \mathrm{C}$ NMR methods.

Figure 5 shows the CP/MAS ${ }^{13} \mathrm{C}$ NMR spectra of the $\mathrm{BMI} / \mathrm{TPP}$ system cured at different temperatures. No change in the spectrum of BMI was observed after treatment at $120^{\circ} \mathrm{C}$ for $10 \mathrm{~min}$. The spectrum of BMI/TPP system cured at $175^{\circ} \mathrm{C}$ or $250^{\circ} \mathrm{C}$ showed a new carbonyl peak at $176 \mathrm{ppm}$, and a new broad signal around $45 \mathrm{ppm}$ ascribed to a methyne carbon formed by the polymerization of double bond of maleimide. These results suggest that the curing reaction does not proceed at $120^{\circ} \mathrm{C}$, but maleimides polymerize at $175^{\circ} \mathrm{C}$ or $250^{\circ} \mathrm{C}$.

The curing reaction of $\mathrm{BMI} / \mathrm{DABA} / \mathrm{TPP}$ system was investigated. Figure 6 shows the liquid ${ }^{13} \mathrm{C}$ NMR spectrum of BMI/DABA with the assignment of each signal. On the basis of the data, assignments of CP/MAS spectra of BMI/DABA/TPP were carried out. Figure 7 shows the $\mathrm{CP} / \mathrm{MAS}{ }^{13} \mathrm{C}$ NMR spectra of the $\mathrm{BMI} /$ DABA/TPP systems cured at different temperatures. The spectrum of the BMI/DABA/TPP system cured at $120^{\circ} \mathrm{C}$ showed a carbonyl peak around $175 \mathrm{ppm}$ and new peaks at $50 \mathrm{ppm}$ and $54 \mathrm{ppm}$ ascribed to methyne and quarternary carbons formed by the trimerization of maleimide, but the signal $45 \mathrm{ppm}$ due to the polymerization was not observed. The curing reactions of the $\mathrm{BMI} / \mathrm{DABA} / \mathrm{TPP}$ systems proceeded rapidly at $120^{\circ} \mathrm{C}$, where the trimerization of $\mathrm{BMI}$ was a chief reaction.

DABA seemed not to change at all in the curing reaction, and thus unreacted DABA was removed from the BMI/DABA/TPP systems cured at $175^{\circ} \mathrm{C}$ and $250^{\circ} \mathrm{C}$ 


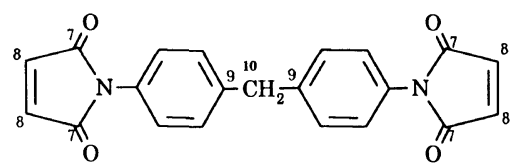

7. $170 \mathrm{ppm},(172 \mathrm{ppm}) \quad 8 .(134 \mathrm{ppm})$

9. $140 \mathrm{ppm}$ 10. $41 \mathrm{ppm}$

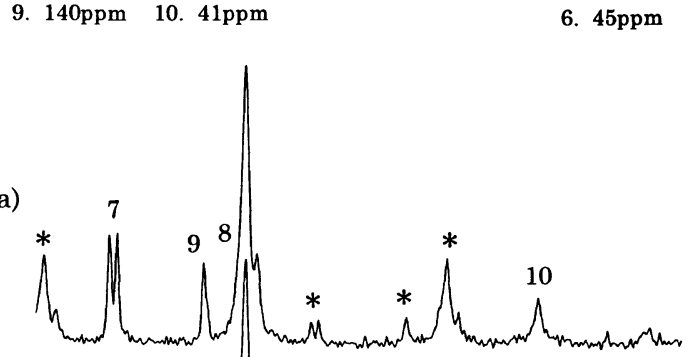

b)

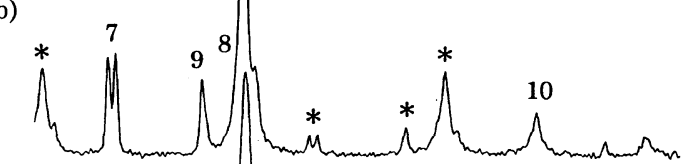

c)

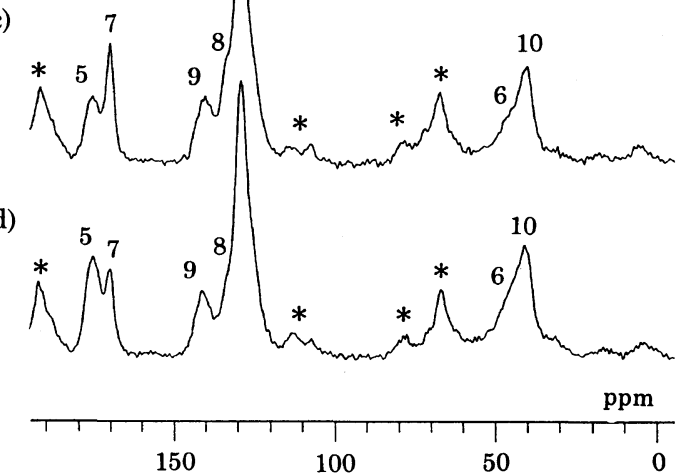

Figure 5. $\mathrm{CP} / \mathrm{MAS}{ }^{13} \mathrm{C}$ NMR spectra of BMI/TPP systems cured at different temperatures: (a) uncured $\mathrm{BMI}$; (b) at $120^{\circ} \mathrm{C}$ for $10 \mathrm{~min}$; (c) at $175^{\circ} \mathrm{C}$ for $10 \mathrm{~min}$; (d) at $250^{\circ} \mathrm{C}$ for $10 \mathrm{~min}$. (* SSB; spinning side band)
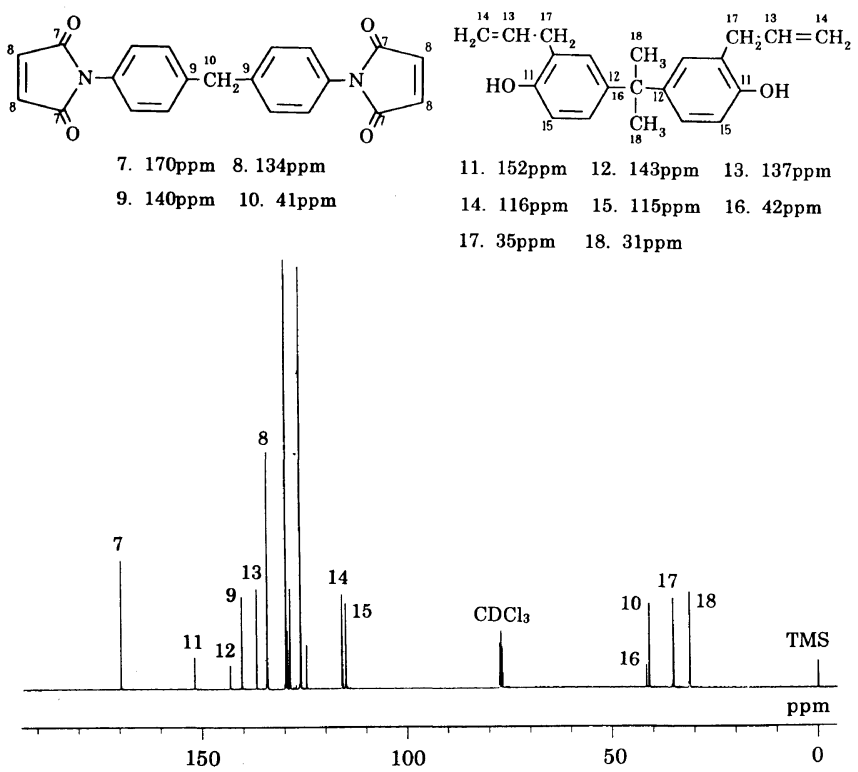

Figure 6. ${ }^{13} \mathrm{C}$ NMR spectrum of the mixture of BMI and DABA in chloroform- $d$.

by extraction with acetone and the residue was analyzed in the $\mathrm{CP} / \mathrm{MAS}{ }^{13} \mathrm{C}$ NMR spectra (Figure 8). The signal of DABA was observed at $152 \mathrm{ppm}$ in the spectrum of<smiles>CCc1ccc(N2C(=O)C=CC2=O)cc1</smiles><smiles>C=CCc1cc(C(C)(C)C)ccc1O</smiles>

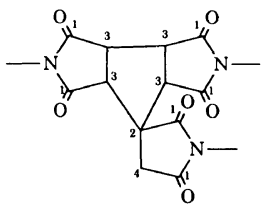

11. $152 \mathrm{ppm}$ 14. $116 \mathrm{ppm}$

15. $115 \mathrm{ppm}$ 16. $42 \mathrm{ppm}$

1. $176 \mathrm{ppm}$ 2. $55 \mathrm{ppm}$

17. $35 \mathrm{ppm}$ 18. $31 \mathrm{ppm}$

a)

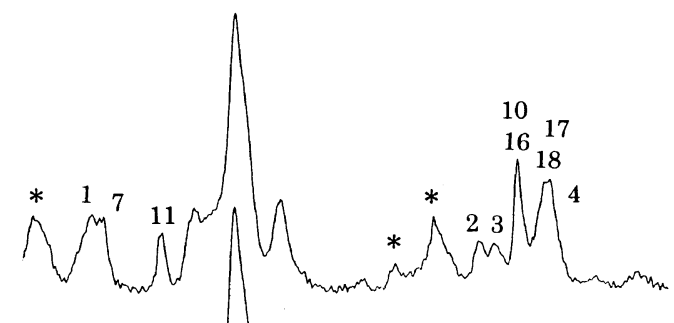

b)

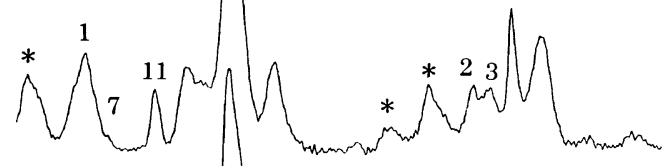

c)
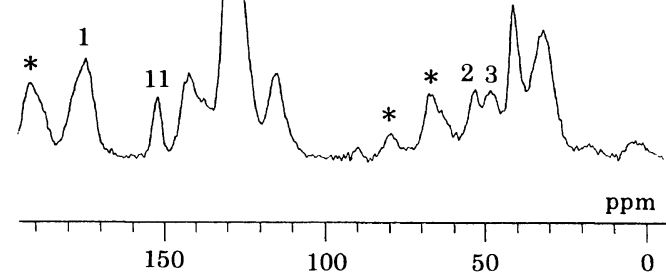

Figure 7. $\mathrm{CP} / \mathrm{MAS}{ }^{13} \mathrm{C}$ NMR spectra of $\mathrm{BMI} / \mathrm{DABA} / \mathrm{TPP}$ systems cured at different temperatures: (a) at $120^{\circ} \mathrm{C}$ for $10 \mathrm{~min}$; (b) at $175^{\circ} \mathrm{C}$ for $10 \mathrm{~min}$; (c) at $250^{\circ} \mathrm{C}$ for $10 \mathrm{~min}$. (* SSB)

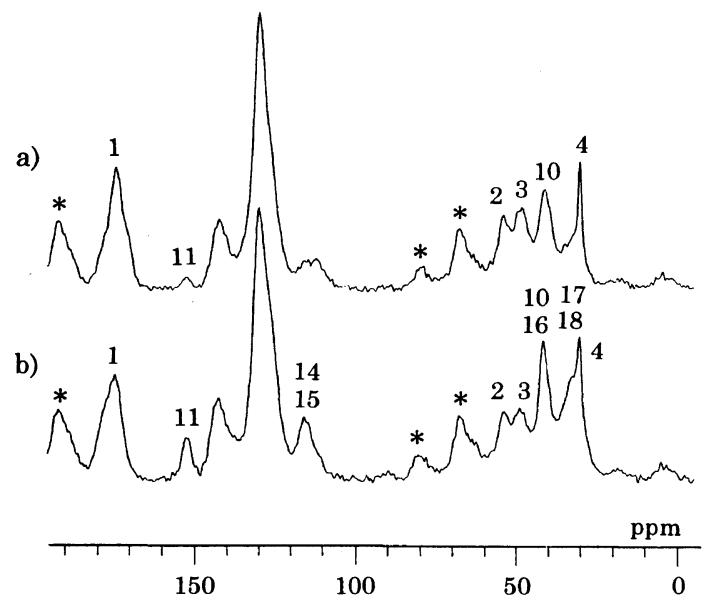

Figure 8. $\mathrm{CP} / \mathrm{MAS}{ }^{13} \mathrm{C}$ NMR spectra of the residues removed unreacted DABA from BMI/DABA/TPP systems by extraction with acetone: (a) BMI/DABA/TPP system cured at $175^{\circ} \mathrm{C}$ for $10 \mathrm{~min}$; (b) the system cured at $250^{\circ} \mathrm{C}$ for $10 \mathrm{~min}$.

the residue from the sample cured at $250^{\circ} \mathrm{C}$ but a very small signal at this region was observed in the sample cured at $175^{\circ} \mathrm{C}$. This means that DABA did not take part in the co-polymerization at $175^{\circ} \mathrm{C}$ but did at $250^{\circ} \mathrm{C}$.

In Figure 9, the dependence of the conversion of maleimide on curing temperature is shown, calculated from the ratio of the peak area at $175 \mathrm{ppm}$ (reacted maleimide carbonyl) and that at $170 \mathrm{ppm}$ (unreacted maleimide carbonyl). In the BMI/TPP system, maleimides is not polymerize at $120^{\circ} \mathrm{C}$, but did so above 


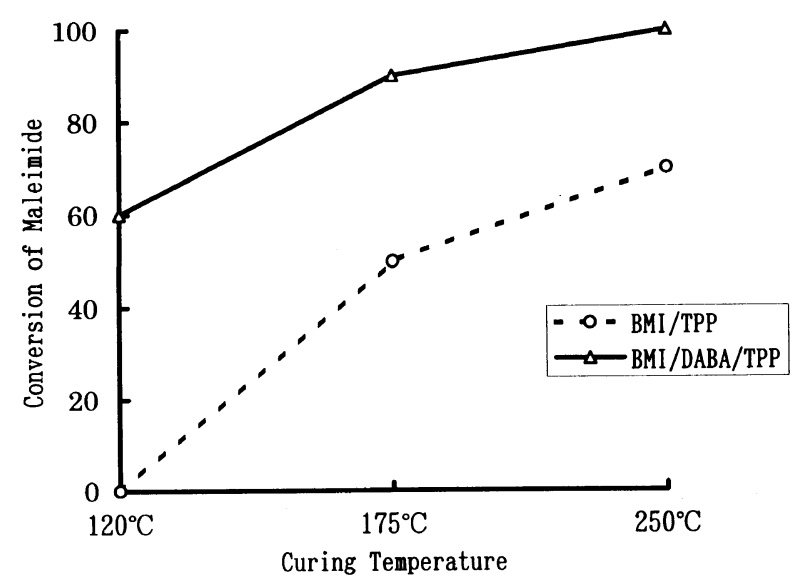

Figure 9. Dependence of the conversion of maleimide, calculated from the ratio of the peak area at $175 \mathrm{ppm}$ (reacted maleimide carbonyl) and that at $170 \mathrm{ppm}$ (unreacted maleimide carbonyl) in $\mathrm{CP} / \mathrm{MAS}{ }^{13} \mathrm{C}$ NMR spectra, on curing temperatures: a $(O)$ BMI/TPP systems; b $\triangle$ ( $\mathrm{BMI} / \mathrm{DABA} / \mathrm{TPP}$ systems.

$175^{\circ} \mathrm{C}$. On the other hand, in the presence of DABA the trimerization of maleimides proceeded at $120^{\circ} \mathrm{C}$. On the basis of this information, we considered peaks observed by DSC (Figure 1). The exothermic peak at $168^{\circ} \mathrm{C}$ observed by DSC of the BMI/TPP system arises from the polymerization of maleimides and the peak at $111^{\circ} \mathrm{C}$ in $\mathrm{BMI} / \mathrm{DABA} / \mathrm{TPP}$ system arises from the trimerization of maleimides.

The curing reactions agreed with the model reactions, where both DABA and TPP catalyzed the trimerization of BMI at lower temperature.

\section{Reactions of Maleimides with Phenolic Hydroxyl Group Catalyzed TPP and Plausible Mechanism of Trimeriza- tion}

We studied the effects of the phenolic hydroxyl group on the trimerization of maleimides catalyzed by TPP. For this purpose, the reaction of hydroxyphenylmaleimides (HPMI) with a hydroxyl group at para position was carried out in the presence of TPP.

Figure 10 shows the liquid ${ }^{13} \mathrm{C}$ NMR spectrum of the reaction products formed after heating at $175^{\circ} \mathrm{C}$ for $10 \mathrm{~min}$. This spectrum showed the four peaks at 30,48 , 51 , and $53 \mathrm{ppm}$ due to the trimer of maleimides. Considering that PMI did not give the trimer at this temperature, the phenolic hydroxyl group of HPMI clearly promoted the trimerization of maleimide.

By this new aspect of HPMI, the curing reactions of bismaleimide resins with phenolic hydroxyl group can be carried out at lower temperature. Thus, newly formed resins with different crosslinking structures are expected to show interesting properties.

The trimerization mechanism of maleimides catalyzed by TPP and phenolic compounds is shown in Figure 11. Hedaya $^{13}$ reported that maleimides react with TPP to give ylide in the presence of protic media such as acetic acid. Enoki ${ }^{16}$ described that the protic solvents such as cresol or acetic acid make easy the addition of an amine to a maleimide without forming the polymer. These reports support that the presence of phenolic hydroxyl group accelerates the addition of TPP to maleimides and the nucleophilic attack of ylide to the double bonds of maleimides, but inhibits polymerization. To examine the
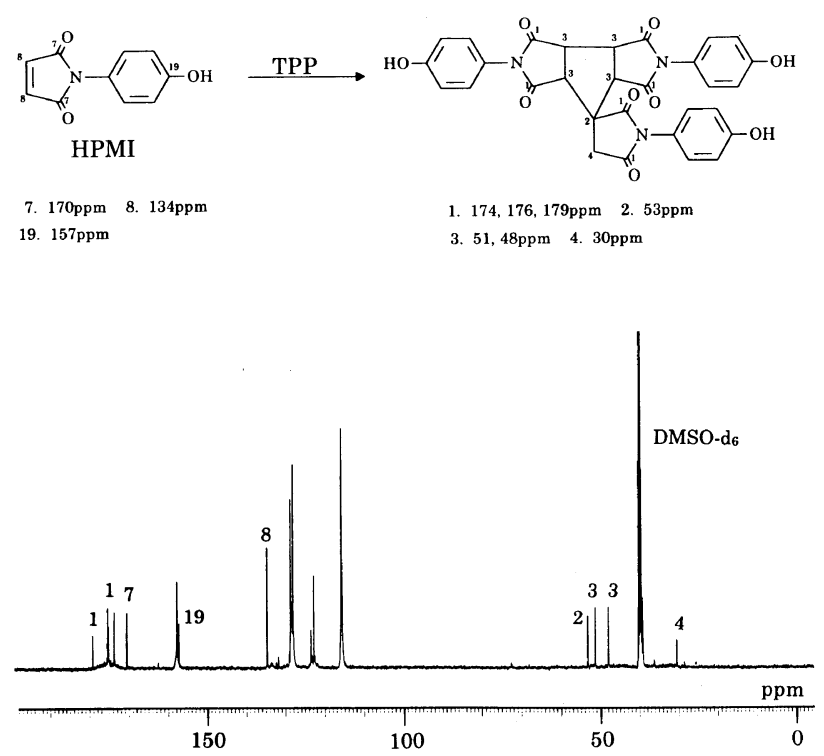

Figure 10. ${ }^{13} \mathrm{C}$ NMR spectrum of the reaction product of $p$-hydroxyphenyl-maleimide (HPMI) catalyzed by TPP in dimethylsulfoxide- $d_{6}$.

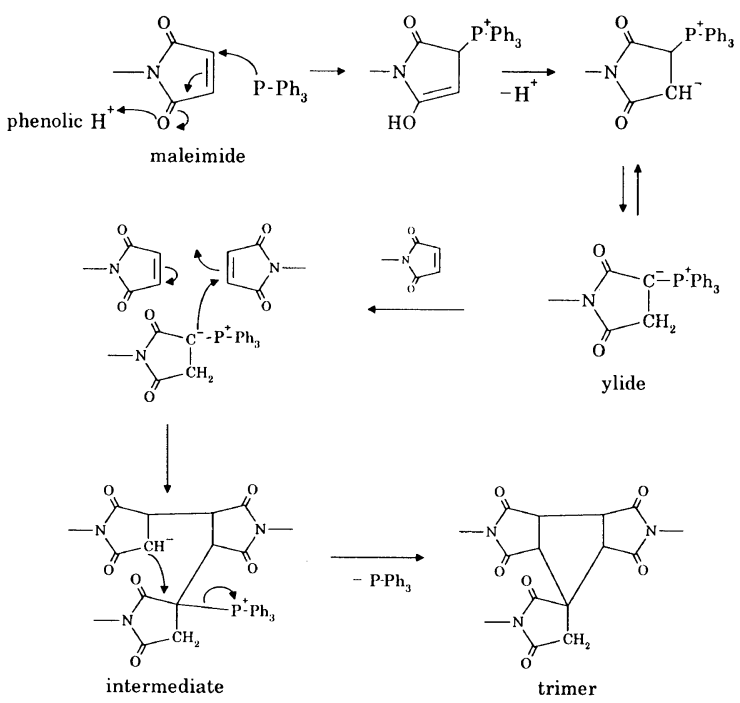

Figure 11. Trimerization mechanisms of maleimide.

adequacy of this reaction mechanism, we confirmed that the PMI trimer was formed by the reaction of PMI with the phosphorus ylide, $N$-phenyltriphenylphosphoranylidenesuccinimide, in the presence of phenol. This ylide is a postulated intermediate of the maleimide trimerization. The easy formation of the five-membered ring by trimerization of maleimides would depend on the configuration of the intermediate, in which two carbons approached each other to achieve a ring closure followed by an elimination of TPP.

\section{CONCLUSION}

The curing reactions of bismaleimide resins catalyzed by TPP were clarified by high resolution solid state ${ }^{13} \mathrm{C}$ NMR techniques, referring to model reactions. In the bismaleimide resin systems without phenols such as $o, o^{\prime}$-diallylbisphenol-A (DABA), maleimides polymerize above $175^{\circ} \mathrm{C}$, but polymerization does not proceed at $120^{\circ} \mathrm{C}$. On the other hand, in the bismaleimide resin with DABA or the maleimides containing phenolic hydroxyl 
group, maleimides trimerize at lower temperature. The structure of the trimer has the five-membered ring containing spiro-ring. High resolution solid state ${ }^{13} \mathrm{C}$ NMR was found very useful for distinguishing crosslinked structures by the trimerization of maleimides and polymerization.

\section{REFERENCES}

1. K. Ishii, Netsukoukasei Jushi, 14, 131 (1993).

2. H. D. Stenzenberger, M. Herzog, W. Romer, R. Scheiblich, S. Pierce, and M. Canning, 30th National SAMPE (Society for the Advancement of Material and Processing Engineering) Symposium, 30, 1568 (1985).

3. J. V. Crivello, J. Polym. Sci., Polym. Chem. Ed., 11, 1185 (1973).

4. J. Schaefer and E. O. Stejskal, J. Am. Chem. Soc., 98, 103 (1976).

5. S. Tsuge, Netsukoukasei Jushi, 11, 31 (1990).
6. S. Shibahara and T. Enoki, Netsukoukasei Jushi, 11, 87 (1990).

7. S. Shibahara and T. Enoki, Netsukoukasei Jushi, 12, 87 (1991).

8. S. Shibahara, T. Yamamoto, S. Tatsumiya, and M. Miki, Netsukoukasei Jushi, 12, 156 (1992).

9. K. Ishii, T. Enoki, and S. Shibahara, Netsukoukasei Jushi, 9, 67 (1988).

10. T. Enoki, T. Takeda, and K. Ishii, High Perform. Polym., 6, 385 (1994).

11. T. Enoki, K. Ishii, and S. Shibahara, Netsukoukasei Jushi, 10, 213 (1989).

12. T. Enoki, K. Ishii, H. Okubo, and S. Shibahara, Netsukoukasei Jushi, 12, 9 (1991).

13. E. Hedaya and S. Theodoropulos, Tetrahedron., 24, 2241 (1968).

14. T. Enoki, H. Okubo, T. Takeda, and K. Ishii, Netsukoukasei Jushi, 16, 94 (1995).

15. C. Maes, J. Devaux, R. Legras, and I. W. Parsons, J. Polym. Sci. A, Polym. Chem., 33, 1943 (1995).

16. T. Enoki, T. Takeda, and K. Ishii, Netsukoukasei Jushi, 16, 86 (1995). 